Pacific Journal of Mathematics

ON MULTIDIMENSIONAL INTEGRAL EQUATIONS OF 


\title{
ON MULTIDIMENSIONAL INTEGRAL EQUATIONS OF VOLTERRA TYPE
}

\author{
M. B. Suryanarayana
}

It is the purpose of this paper to study multidimensional nonlinear integral equations of Volterra type of a rather general form with unknowns in one of the function spaces $C, L_{1}, L_{\infty}$ or $L_{p}, 1<p<+\infty$. In analogy with the theory of differential equations, global existence and uniqueness theorems as well as continuous dependence on initial values, are established for such integral equations. The hypotheses on integrands in this paper are less demanding than normally found in the literature and are motivated by applications, particularly to boundary value problems found in optimal control theory.

Since the literature on multidimensional integral equations of Volterra type is very extensive (see N. V. Kasatkina [5], W. Walter [10], Arthur Wouk [11] for partial surveys), we shall incorporate below certain relevant remarks on these equations and also briefly describe the general form of the integral equations studied in this paper.

The integral equation

$$
z(x, y)=\phi(x)+\psi(y)-\phi(0)+\int_{0}^{x} \int_{0}^{y} f\left(\alpha, \beta, z, z_{x}, z_{y}\right) d \alpha d \beta
$$

is well-known since it corresponds to the classical Darboux problem

$$
z_{x y}(x, y)=f\left(x, y, z, z_{x}, z_{y}\right),(x, y) \in[0, h] \times[0, k],
$$

with boundary data

$$
z(x, 0)=\dot{\phi}(x) ; z(0, y)=\psi(y) ; \phi(0)=\psi(0) .
$$

The above equation is clearly with two independent variables $x$ and $y$.

For the the multidimensional $(m>2)$ equations, several forms have been proposed in the past. One such form, studied by W. Walter [10], is

$$
\begin{aligned}
& u_{\nu}(x)=g_{\nu}(x)+\int_{H_{\nu}(x)} k_{\nu}(x, \xi, u(\xi))(d \xi)_{p_{\nu}} \\
& u=\left(u_{1}, u_{2}, \cdots, u_{n}\right), \nu=1,2, \cdots, n, x \in B \subset E^{m},
\end{aligned}
$$

where $H_{\nu}(x) \subset B(x)=\left\{\xi \in B \mid \xi_{i} \leqq x_{i}, i=1,2, \cdots n\right\}$. Precisely, $H_{\nu}(x)$ is assumed by Walter to be contained in a $p_{\nu}$-dimensional hyperplane, $1 \leqq p_{\nu} \leqq m$, parallel to the coordinate axes-i.e., in a translate of the linear manifold generated by $p_{\nu}$ of the basis vectors $(1,0, \cdots, 0),(0$, 
$1,0 \cdots 0), \cdots(0,0, \cdots 0,1)$ in $E^{m}$. W. Walter gave theorems for the existence of continuous solutions for such systems.

One is now directed naturally to equations where the set $H_{\nu}$ need not be in a $p_{\nu}$-dimensional hyperplane (with nonzero measure). In other words, one may consider equations where $H_{\nu}$ may consist of several sets, each of which belongs to a hyperplane of different dimension. An example of such an equation would be

$$
\begin{aligned}
\phi(x, y) & =f(x, y)+\int_{0}^{x} A(x, y, s) \phi(s, y) d s \\
& +\int_{0}^{y} B(x, y, t) \phi(x, t) d t+\int_{0}^{x} \int_{0}^{y} C(x, y, s, t) \phi(s, t) d s d t
\end{aligned}
$$

which is not of the form (1.2) [see T. H. Gronwall [3]].

N. V. Kasatkina [5] in the lines of R. H. J. Germay [12], has studied the following more general integral equation for local uniqueness of continuous solutions:

$$
\begin{aligned}
& x(t)=\sum_{\substack{1 \leqq i_{1} \leqq \cdots \leq i_{k} \leqq n \\
1 \leqq k \leqq n}} \int_{a_{i_{1}}}^{t_{i_{1}}} \cdots \int_{a_{i_{k}}}^{t_{i_{k}}} K_{i_{1} \cdots i_{k}}\left(t, s_{i_{1} \cdots i_{k}},\right. \\
& \left.x\left(t_{1}, t_{2} \cdots t_{i_{1}-1}, s_{i_{1}}, t_{i_{1}+1}, \cdots t_{i_{k}-1}, s_{i_{k}}, \cdots t_{n}\right)\right) d s_{i_{1}} \cdots d s_{i_{k}}+f(t)
\end{aligned}
$$

where $t=\left(t_{1}, t_{2} \cdots t_{n}\right), s_{i_{1} \cdots i_{k}}=\left(s_{i_{1}}, s_{i_{2}} \cdots s_{i_{k}}\right)$. His method involves differential inequalities and the results hold locally.

The integral equations studied in this paper are of the same general form as (1.4), but with unknowns in spaces $L_{p}, 1 \leqq p \leqq \infty$, and not necessarily in $C$, as is usual. Besides, we require less demanding hypotheses on the integrands.

The canonical form, emphasized in the present discussion, seems to be the most general since it is found that many equations considered in the past can be put into this form. The theorems we obtain are global and not local. Further, an analogy with the usual theory of differential equations is maintained as far as possible.

The proofs in the present paper are based on fixed point theoremsprecisely, on an extension of Banach's contraction theorem. Indeed, the equations under consideration-being of Volterra type-give rise to an operator $T$ which is not necessarily a contraction by itself; but suitable powers of $T$ are so. It is seen that still, there exists a fixed point for $T$, by a remark of F. F. Bonsall [1]. This fact allows us to relax the hypotheses.

Essentially, the same argument applies to the space $C$ of continuous functions, as well as to the spaces $L_{p}$ of the $p^{\text {th }}$ summable functions, for $1 \leqq p \leqq \infty$, and in each of all these cases, we assume a different set of hypotheses. If the equations are assumed to be 
linear, with analytic coefficients, then existence of analytic solutions is obtained by applying the argument to a space of analytic functions.

The results of this paper are used in-and the present paper has been motivated by-problems of optimal control monitored by nonlinear system (1.1) (and corresponding Darboux data), particularly since the controls are known to be only measurable, and hence the integrandswhich contain the controls - may be assumed, at best, to be in some $L_{p}$-space, $1 \leqq p \leqq \infty$. Besides, the corresponding Pontryagin-type multipliers are known to satisfy linear Volterra-type integral equations of the same form (1.4), but again with integrands in an $L_{p}$-space.

In $\S 2$ we develop suitable notations, in $\S 3$ we summarize basic statements, in particular Bonsall's remark, in $\S 4$ we discuss the problem under consideration in class $C$, in $\$ 5$ we show that analogous results and essentially same proofs using Bonsall's remark hold in $L_{p}, 1 \leqq p \leqq \infty$; in $\S 6$ we consider the linear case and show the existence of analytic solutions, in harmony with classical results. Applications to control problems will be given elsewhere. The special case of the classical Darboux problem (1.1) is discussed in the appendix.

2. Notations. Let $E^{n}$ denote the $n$-dimensional Euclidean space. Let $G=\left\{t \in E^{n} \mid t=\left(t_{1}, t_{2}, \cdots t_{n}\right), a_{i} \leqq t_{i} \leqq a_{i}+h_{i}, i=1,2 \cdots n\right\}$. Let $\alpha$ denote the multiindex $\left(\alpha_{1}, \alpha_{2}, \cdots \alpha_{n}\right)$ with arbitrary nonnegative integers $\alpha_{i}, i=1,2 \cdots n$. As usual, $|\alpha|=\alpha_{1}+\alpha_{2}+\cdots \alpha_{n}$, and $\alpha !=\alpha_{1} ! \alpha_{2} ! \cdots \alpha_{n} !$. Given any $\alpha$, let $\beta_{j}$ denote the index of the $j^{\text {th }}$ nonzero element of the sequence $\left(\alpha_{1}, \alpha_{2} \cdots \alpha_{n}\right)$. Let us consider the multiindex $\beta=\left(\beta_{1}, \beta_{2}, \cdots, \beta_{k}\right) ; k$ being some integer with $1 \leqq k \leqq n$, determined by $\alpha$. We shall say that $\beta$ corresponds to $\alpha$. Thus, for example, $(2,5)$ corresponds to $(0,1,0,0,2) ;(1,3,6,7)$ corresponds to $(1,0,1,0,0,1,1)$, etc. For $t \in E^{n}$, let $t_{\beta}$ denote $\left(t_{\beta_{1}}, t_{\beta_{2}} \cdots t_{\beta_{k}}\right)$ and let $t_{\beta}^{\prime}=\left(t_{1}, t_{2} \cdots t_{\beta_{1}-1}, t_{\beta_{1}+1}, \cdots t_{\beta_{k^{-1}}}, t_{\beta_{k}+1}, \cdots, t_{n}\right)$. In particular let $t_{i}^{\prime}=$ $\left(t_{1}, t_{2} \cdots t_{i-1}, t_{i+1}, t_{n}\right)$. Let $G_{\beta}=\left\{s_{\beta} \in E^{k} \mid s_{\beta}=\left(s_{\beta_{1}}, s_{\beta_{2}}, \cdots, s_{\beta_{k}}\right), a_{i} \leqq s_{i} \leqq\right.$ $\left.a_{i}+h_{i} ; i=\beta_{1}, \beta_{2} \cdots \beta_{k}\right\}$. Let $\pi(\theta)=\pi\left(\theta_{1}, \theta_{2} \cdots \theta_{n}\right)=\sum_{1 \leqq|\alpha| \leqq N} \lambda_{\alpha} \theta^{\alpha}$ denote a polynomial of degree $N$ in $\theta$ with no constant term. Here $\theta^{\alpha}$ denotes $\theta_{1}^{\alpha_{1}} \theta_{2}^{\alpha_{2}} \cdots \theta_{n}^{\alpha_{n}}$.

Let $C(G)$ denote as usual the space of functions continuous on $G$, with supnorm and let $L_{p}(G)$ be the space of the $p$ th summable functions for $1 \leqq p<\infty$ and $L_{\infty}(G)$ be the space of all essentially bounded measurable functions on $G$. For $m \geqq 1$ and $X=C(G), L_{p}(G)$ or $L_{\infty}(G)$, let $X^{m}=X \times X \cdots X(m$ times $)$ and for $\varphi=\left(\varphi_{1}, \varphi_{2} \cdots \varphi_{m}\right)$ in $X^{m}$ let $\|\varphi\|=\sum_{i=1}^{m}\left\|\varphi_{i}\right\|$. We shall denote by $\|\varphi\|_{c},\|\varphi\|_{p}$ and $\|\varphi\|_{\infty}$ the norms in $[C(G)]^{n},\left[L_{p}(G)\right]^{m}$ and $\left[L_{\infty}(G)\right]^{m}$, respectively.

For $i=1,2 \cdots n$, let $T_{i}$ be an operator defined on $X^{m}$ (with $X=$ $C(G), L_{p}(G)$ or $L_{\infty}(G)$ ) as follows: 


$$
T_{i} \varphi(t)=\int_{a_{i}}^{t_{i}} \varphi\left(t_{i}^{\prime}, s\right) d s, \varphi \in X^{m} .
$$

We define the product $T_{i} T_{j}$ as composition, so that $T_{i}^{r} \varphi=T_{i}\left(T_{i}^{r-1} \varphi\right)$, $r \geqq 1$ and $T_{i}^{0} \varphi=\varphi ; \varphi \in X^{m}$. By using Hölder's inequality, it is seen that

$$
\left\|\boldsymbol{T}_{i}^{r} \varphi\right\|_{p} \leqq\|\varphi\|_{p} h_{i}^{r}\left(r ! p^{r}\right)^{-1 / p}, 1 \leqq p<\infty
$$

and

$$
\left\|T_{i}^{r} \varphi\right\|_{\infty} \leqq\|\varphi\|_{\infty} h_{i}^{r}(r !)^{-1}
$$

Also,

$$
\left\|T_{i}^{r} \varphi\right\|_{c} \leqq\|\varphi\|_{c} h_{i}^{r}(r !)^{-1}
$$

For any multiindex $\alpha=\left(\alpha_{1}, \alpha_{2} \cdots \alpha_{n}\right)$ as in the beginning of this section, we shall denote by $T^{\alpha}$ the operator $T_{1}^{\alpha_{1}} \cdots T_{n}^{\alpha_{n}}$; and given any polynomial $\pi(\theta)=\sum \lambda_{\alpha} \theta^{\alpha}$ of degree $N$, we shall denote by $\pi(T)$ the operator $\sum \lambda_{\alpha} T^{\alpha} \equiv \sum \lambda_{\left(\alpha_{1}, \alpha_{2} \cdots \alpha_{n}\right)} T_{1}^{\alpha_{1}} T_{2}^{\alpha_{2}} \cdots T_{n}^{\alpha_{n}}$.

In this paper we shall consider the following (canonic) form of multidimensional integral equations of Volterra type:

$$
\begin{aligned}
x(t) & =f(t)+\left(\pi(T) \circ F^{\prime}\right)(x)(t) \\
& =f(t)+\sum_{1 \leqq|\alpha| \leqq N} \lambda_{\alpha} T^{\alpha} F_{\alpha}\left(t, s_{\beta}, x\left(t_{\beta}^{\prime}, s_{\beta}\right)\right)
\end{aligned}
$$

where $f(t) \in X^{m}$ and for each $\alpha$, with $1 \leqq|\alpha| \leqq N$, the function $F_{\alpha}(t$, $\left.s_{\beta}, x\right)=\left(F_{\alpha}^{1}, F_{\alpha}^{2} \cdots F_{\alpha}^{m}\right)$ is defined on $G \times G_{\beta} \times E^{m}$ and here $\beta$ is the multiindex corresponding to $\alpha$, as described earlier. Specific assumptions on $f$ and $F_{\alpha}$ will be made later.

3. Preliminaries. In the sequel, we shall need a few preliminary statements. They are given below:

If $F: X \rightarrow Y$ is a mapping of a metric space $(X, \rho)$ into another metric space $(Y, \sigma)$ and there is a constant $c>0$ such that $\sigma\left(F x_{1}, F x_{2}\right) \leqq$ $c \rho\left(x_{1}, x_{2}\right)$ for all $x_{1}, x_{2} \in X$, then we denote by $\nu(F)$ the number sup $\left\{\sigma\left(F x_{1}, F x_{2}\right) / \rho\left(x_{1}, x_{2}\right): x_{1}, x_{2} \in X, x_{1} \neq x_{2}\right\}$.

(3. i) (An extension of Banach's contraction mapping theorem) (see F. F. Bonsall [1]): Let $F: X \rightarrow X$ be a complete metric space $(X, \rho)$ into itself. Let $F^{1}=F$ and $F^{n}=F\left(F^{n-1}\right)$ for $n>1$. Let us assume that $\nu\left(F^{n}\right)<+\infty$ for every $n$ and that $\sum_{n=1}^{\infty} \nu\left(F^{n}\right)<\infty$. Then $F$ has a unique fixed point $x_{0} \in X$.

(3. ii) (F. F. Bonsall, [1]): If $F: X \rightarrow X$ is any continuous map of a complete metric space $(X, \rho)$ into itself such that for some integer 
$N \geqq 1, F^{N}$ is a contraction on $X$, then $F$ has a unique fixed point $x_{0}$ in $X$.

(3. iii) Let $G=\left\{t \in E^{n} \mid t=\left(t_{1}, t_{2} \cdots t_{n}\right), a_{i} \leqq t_{i} \leqq a_{i}+h_{i}, i=1,2 \cdots\right.$ $n\}$ as in $\S 2$ and let $G_{i}=\left\{s \in E^{1}: a_{i} \leqq s \leqq a_{i}+h_{i}\right\} i=1,2 \cdots n$. Let $\varphi=\varphi(t, s)$ be a real valued function defined on $G \times G_{i}$ such that

(a) $|\varphi(t, s)| \leqq c m(s)$ for all $(t, s) \in G \times G_{i}$ where $c$ is a constant and $m(s)$ is integrable on $G_{i}$.

(b) $\varphi$ is continuous in $t$ for each fixed $s \in G_{i}$.

(c) $\phi$ is measurable in $s$ for each fixed $t \in G$.

Then the function $T_{i} \varphi(t)=\int_{a_{i}}^{t_{i}} \varphi(t, s) d s$ is continuous on $G$.

Following the notation of $\S 2$, if $T_{i}, i=1,2 \cdots n$ are the operators defined there, if $\alpha=\left(\alpha_{1}, \alpha_{2} \cdots \alpha_{n}\right)$ is any multiindex, $T^{\alpha}=T_{1}^{\alpha_{1}} \cdots T_{n}^{\alpha_{n}}$ and $\beta$ is the multiindex corresponding to $\alpha$, then $T^{\alpha} \varphi\left(t, s_{\beta}\right) \in[C(G)]^{m}$, provided

(a) $\left|\varphi\left(t, s_{\beta}\right)\right| \leqq c m\left(s_{\beta}\right)$ for all $\left(t, s_{\beta}\right) \in G \times G_{\beta}$.

(b) $\phi$ is continuous in $t$ for each fixed $s_{\beta} \in G_{\beta}$.

(c) $\varphi$ is measurable in $s_{\beta}$ for each fixed $t \in G$.

(3. iv) Let $\alpha=\left(\alpha_{1}, \alpha_{2} \cdots \alpha_{n}\right)$ be any multiindex and let $\beta=\left(\beta_{1}\right.$, $\left.\beta_{2} \cdots \beta_{k}\right)$ correspond to $\alpha$ as in $\S 2$. Let $\varphi\left(t, s_{\beta}\right)$ be any real valued function on $G \times G_{\beta}$ which is continuous in $t_{\beta}$ for almost all $\left(t_{\beta}^{\prime}, s_{\beta}\right) \in G$ and belongs to $L_{1}(G)$ for each fixed $t_{\beta} \in G_{\beta}$. Let there exist a constant $B \geqq 0$ and a function $m\left(t_{\beta}^{\prime}, s_{\beta}\right)$ in $L_{1}(G)$ such that for $\left(t, s_{\beta}\right) \in G \times G_{\beta}$ we have $\left|\varphi\left(t, s_{\beta}\right)\right| \leqq B m\left(t_{\beta}^{\prime}, s_{\beta}\right)$. Then the function $\Phi(t)$ defined by $\Phi(t)=$ $T^{\alpha} \varphi\left(t, s_{\beta}\right)$, is measurable on $G$.

Let $B_{1}$ be a measurable subset of $E^{n}$ and let $g_{i}(x, y), i=1,2 \ldots$ $m$ be realvalued measurable functions on $B_{1} \times E^{r}$. Let $p_{1}$ and $p_{2}$ be two real numbers with $1 \leqq p_{1}, p_{2}<\infty$. Let us consider the following condition:

(H) There exist $m$ functions $a_{i}(x), i=1,2 \cdots m$, in $L_{p_{2}}\left(B_{1}\right)$ and a constant $b \geqq 0$ such that for each $i=1,2 \cdots m$, we have

$$
\left|g_{i}(x, y)\right| \leqq a_{i}(x)+b|y|^{p_{1} / p_{2}} \text {. }
$$

(3. v) (see M. A. Krasnoselskii, [6]) Let $B_{1}$ be a measurable subset of $E^{n}$ and let $g_{i}(x, y), i=1,2 \cdots m$ be real valued functions on $B_{1} \times$ $E^{r}$ such that for each $i, g_{i}(x, y)$ is continuous on $E^{r}$ with respect to $y$ for almost all $x$ in $B_{1}$, and measurable in $x$ for each fixed $y$ in $E^{r}$. Let $J z=\left(J_{1} z, J_{2} z, \cdots J_{m} z\right)$ with $J_{i} z(x)=g_{i}(x, z(x))$. Then $J z$ is measurable whenever $z$ is measurable. Furthermore, the operator $J$ maps $\left[L_{p_{1}}\left(B_{1}\right)\right]^{r}$ into $\left[L_{p_{2}}\left(B_{1}\right)\right]^{m}$ if and only if condition $(\mathrm{H})$ holds.

Following the terminology of R. C. Gunning and H. Rossi [4], a complex valued function $f$ defined on an open subset $B \subset C^{n}$ (the $n$ - 
dimensional complex vector space) is called "holomorphic" in $B$ if each point $w \in B$ has an open neighborhood $U, w \in U \subset B$, such that the function $f$ has a power series expansion $f(z)=\sum_{\nu_{1}, \nu_{2} \cdots \nu_{n}=0}^{\infty} a_{\nu_{1} \nu_{2} \cdots \nu_{n}}\left(z_{1}-\right.$ $\left.w_{1}\right)^{\nu_{1}} \cdots\left(z_{n}-w_{n}\right)^{\nu_{n}}$ which converges absolutely for all $z \in U$. A function $f$ is said to be holomorphic on a closed set $D \subset C^{n}$, if $f$ is holomorphic on an open set containing $D$. For functions of several real variables, the same definition above holds, with the word "analytic" being used instead of "holomorphic." The set of all functions holomorphic on $D$ will be denoted by $O(D)$.

If $D$ denotes the rectangle $\left\{\zeta \in C^{n}|| \zeta_{i} \mid \leqq H_{i}, i=1,2 \cdots n\right\} \subset C^{n}$, then we can define a norm on $O(D)$ as:

$$
\|x\|=\sum_{|\alpha|=0}\left|a_{\alpha}\right| H^{\alpha} \text { where } x=\sum_{|\alpha|=0}^{\infty} a_{\alpha} \zeta^{\alpha} \in O(D) .
$$

(3. vi) The set $O(D)$ with the above norm is a Banach space.

4. Continuous solutions. In this section we shall discuss the existence and uniqueness of continuous solutions (as well as the dependence of solutions on the "initial" values) of the canonical system:

$$
x(t)=f(t)+\sum_{1 \leqq \alpha \mid \leqq N} \lambda_{\alpha} T^{\alpha} F_{\alpha}\left(t, s_{\beta}, x\left(t_{\beta}^{\prime}, s_{\beta}\right)\right) .
$$

Theorem 1 below shows the existence of continuous solutions of (2.4) under the assumption that the $F_{\alpha}$ are merely continuous in $x$, and not necessarily linear. In this situation, the modulus of continuity is required to be "small" and suitable bounds are given for the $\lambda_{\alpha}$.

If all $F_{a}$ are known to be Lipschitzian in $x$, the condition of "small modulus of continuity" can be removed due to the fact that the equation (2.4) is of Volterra type, and the $\lambda_{\alpha}$ are then arbitrary. Besides, the solutions are unique in this case. Precise formulations are found in Theorem 2. If $F_{\alpha}$ are linear in $x$, with analytic coefficients $A_{\alpha}$, then solutions can be found which are analytic-not merely continuous. This is in harmony with classical results. This case is studied in $\S 6$.

In order to state a theorem on the existence of continuous solutions of the integral equation (2.4), we shall need the following set of hypotheses:

$\left(\mathrm{H}_{1}\right)$ : Let $f(t)$ be a given element of $[C(G)]^{m}$, and let $M_{1}>0$ be such that $|f(t)| \leqq M_{1}$ for $t \in G$. Let $M_{2}>M_{1}$ and $S_{I_{2}}$ denote $\left\{\zeta \mid \zeta \in E^{m}\right.$, $\left.|\zeta| \leqq M_{2}\right\}$.

$\left(\mathrm{H}_{2}\right)$ : Let $F_{\alpha}\left(t, s_{\beta}, x\right)=\left(F_{\alpha}^{1}, F_{\alpha}^{2} \cdots F_{\alpha}^{m}\right)$ be functions defined on $G \times$ $G_{\beta} \times S_{M_{2}}$ where $\beta=\left(\beta_{1}, \beta_{2}, \cdots \beta_{d_{\alpha}}\right)$ corresponds to $\alpha$, as described in $\S 2$. Let

(a) $F_{\alpha}\left(t, s_{\beta}, x\right)$ be measurable in $s_{\beta}$ for fixed $(t, x)$;

(b) there exist functions $k_{1_{\alpha}}\left(s_{\beta}\right)$ integrable on $G_{\beta}$ such that on $G \times$ 
$G_{\beta} \times S_{M_{2}}$ we have $\left|F_{\alpha}\left(t, s_{\beta}, x\right)\right| \leqq k_{1_{\alpha}}\left(s_{\beta}\right)$.

$\left(\mathrm{H}_{3}\right)$ : There exist monotone nondecreasing continuous functions $w_{i_{\alpha}}$ with $w_{i_{\alpha}}(0)=0, i=1,2$ and functions $\widetilde{k}_{2_{\alpha}}\left(s_{\beta}\right)$ integrable on $G_{\beta}$ such that for $\left(t^{1}, x_{1}\right),\left(t^{2}, x_{2}\right)$ in $G \times S_{M_{2}}$ and $s_{\beta} \in G_{\beta}$, we have

$$
\left|F_{\alpha}\left(t^{1}, s_{\beta}, x_{1}\right)-F_{\alpha}\left(t^{2}, s_{\beta}, x_{2}\right)\right| \leqq \widetilde{k}_{2_{\alpha}}\left(s_{\beta}\right)\left[w_{1_{\alpha}}\left(\left|t^{1}-t^{2}\right|\right)+w_{2_{\alpha}}\left(\left|x_{1}-x_{2}\right|\right)\right] .
$$

It is to be noted that if we take $H_{\alpha}\left(t, s_{\beta}, x\right)=\left(t_{\beta}-s_{\beta}\right)^{\beta-1}((\beta-1) !)^{-1}$ $F_{\alpha}\left(t, s_{\beta}, x\right)$, then we have $T_{\beta} H_{\alpha}=T_{\beta_{1}} \cdot T_{\beta_{2}} \cdots T_{\beta_{d \alpha}}\left(H_{\alpha}\right)=T^{\alpha} F_{\alpha}$. Furthermore, as a consequence of the condition $\left(\mathrm{H}_{3}\right)$ above, there exist functions $k_{2_{\alpha}}\left(s_{\beta}\right)$ integrable in $G_{\beta}$ such that

$$
\begin{aligned}
& \left|H_{\alpha}\left(t^{1}, s_{\beta}, x_{1}\right)-H_{\alpha}\left(t^{2}, s_{\beta}, x_{2}\right)\right| \\
\leqq & k_{2_{\alpha}}\left(s_{\beta}\right)\left[w_{1_{\alpha}}\left(\left|t^{1}-t^{2}\right|\right)+w_{2_{\alpha}}\left(\left|x_{1}-x_{2}\right|\right)\right]
\end{aligned}
$$

for $\left(t^{1}, x_{1}\right),\left(t^{2}, x_{2}\right)$ in $G \times S_{M_{2}}$ and $s_{\beta} \in F_{\beta}$. This is what we shall need in the sequel.

Let $D_{\beta_{i}}$ denote the product of intervals $\left[a_{j}, a_{j}+h_{j}\right]$ for $j=1$, $2 \cdots i-1, i+1, \cdots d_{\alpha}$ where $d_{\alpha}$ is the number of nonzero elements in $\alpha=\left(\alpha_{1}, \alpha_{2} \cdots \alpha_{n}\right)$. Let us consider the functions $K_{i_{\alpha}}\left(t_{\beta_{i}}\right)$ defined on $\left[a_{\beta_{i}}, a_{\beta_{i}}+h_{\beta_{i}}\right]$ as follows:

$$
K_{i_{\alpha}}\left(t_{\beta_{i}}\right)=\int\left(t_{\beta}-s_{\beta}\right)^{\beta-1}((\beta-1) !)^{-1} k_{1_{\alpha}}\left(s_{\beta}\right) d s_{\beta}
$$

where the integration is performed over the set $\left[a_{\beta_{i}}, t_{\beta_{i}}\right] \times D_{\beta_{i}}$ and $k_{1 \alpha}\left(s_{\beta}\right)$ are the functions found in $\left(\mathrm{H}_{2}\right)$. Since $k_{1_{\alpha}}\left(s_{\beta}\right)$ are $L$-integrable in $G_{\beta}$, it follows that the functions $K_{i_{\alpha}}$ are continuous in $\left[a_{\beta_{i}}, a_{\beta_{i}}+h_{\beta_{i}}\right]$. Also, by $\left(\mathrm{H}_{1}\right)$, the function $f$ is continuous on $G$. Thus, there exist monotone nondecreasing functions $\nu(\cdot), \sigma_{i_{\alpha}}(\cdot)$ such that $\nu(0)=0$, $\sigma_{i_{\alpha}}(0)=0$, and

$$
\begin{aligned}
& \left|f\left(t^{1}\right)-f\left(t^{2}\right)\right| \leqq \nu\left(\left|t^{1}-t^{2}\right|\right) \text { and } \\
& \left|K_{i_{\alpha}}\left(t_{\beta_{i}}^{1}\right)-K_{i_{\alpha}}\left(t_{\beta i}^{2}\right)\right| \leqq \sigma_{i_{\alpha}}\left(\left|t_{\beta i}^{1}-t_{\beta i}^{2}\right|\right) .
\end{aligned}
$$

Let $k_{i_{\alpha}}=\int_{G_{\beta}} k_{i_{\alpha}}\left(s_{\beta}\right) d s_{\beta}, i=1,2 ; 1 \leqq|\alpha| \leqq N$.

$\left(\mathrm{H}_{4}\right)$ : Let there exist real numbers $\lambda_{\alpha}$ such that

$$
M_{1}+\sum_{\alpha}\left|\lambda_{\alpha}\right| k_{\alpha} h_{\beta}^{\beta-1}((\beta-1) !)^{-1} \leqq M_{2}
$$

$\left(\mathrm{H}_{5}\right)$ : Let there exist monotone nondecreasing, continuous functions $\eta($.$) vanishing at zero such that$

$$
\eta(\theta) \geqq \zeta(\theta)+\sum_{\alpha}\left|\lambda_{\alpha}\right| k_{2_{\alpha}} w_{2_{\alpha}}(\eta(\theta))
$$


where

$$
\zeta(\theta)=\nu(\theta)+\sum_{\alpha}\left|\lambda_{\alpha}\right|\left[\sum_{i} \sigma_{i \alpha}\left(\left|\theta_{\beta_{i}}\right|\right)+k_{2} w_{i_{\alpha}}(\theta)\right]
$$

and

$$
\theta=\left(\theta_{1}, \theta_{2} \cdots \theta_{n}\right) \text { with } \theta_{i} \in\left[0, h_{i}\right], i=1,2 \cdots n
$$

THeORem 1. Let the above hypotheses $H_{1}-H_{5}$ hold. Let $K$ denote $\left\{x \in[C(G)]^{m}:|x(t)| \leqq M_{2}\right.$ and $\left|x\left(t^{1}\right)-x\left(t^{2}\right)\right| \leqq \eta\left(\left|t^{1}-t^{2}\right|\right)$ for $\left.t^{1}, t^{2} \in G\right\}$. Let $\tau$ be an operator defined on $[C(G)]^{m}$ by

$$
\tau x(t)=f(t)+\sum_{1 \leqq|\alpha| \leqq N} \lambda_{\alpha} T^{\alpha} F_{\alpha}\left(t, s_{\beta}, x\left(t_{\beta}^{\prime}, s_{\beta}\right)\right) .
$$

Then, there exists at least one $x \in K$ with $x=\tau x$.

Proof. The set $K$ defined above is a nonempty compact convex subset of the normed space $[C(G)]^{m}$. Let us prove that $\tau$ maps $K$ into $K$ and that $\tau$ is continuous.

For $x \in K, t^{1}, t^{2} \in G$ with $t_{i}^{1} \leqq t_{i}^{2}, i=1,2 \cdots n$ we have

$$
\begin{aligned}
& \quad\left|x\left(t^{1}\right)-x\left(t^{2}\right)\right| \leqq\left|f\left(t^{1}\right)-f\left(t^{2}\right)\right| \\
& \quad+\sum_{\alpha}\left|\lambda_{\alpha}\left[T^{\alpha} F_{\alpha}\left(t^{1}, s_{\beta}, x\left(t^{1}, s_{\beta}\right)\right)-T^{\alpha} F_{\alpha}\left(t^{2}, s_{\beta}, x\left(t^{2}, s_{\beta}\right)\right)\right]\right| \\
& \leqq \nu\left(\left|t^{1}-t^{2}\right|\right)+\sum_{\alpha}\left|\lambda_{\alpha}\left[T_{\beta} H_{\alpha}\left(t^{1}, s_{\beta}, x\left(t^{1}, s_{\beta}\right)\right)-T_{\beta} H_{\alpha}\left(t^{2}, s_{\beta}, x\left(t^{2}, s_{\beta}\right)\right)\right]\right| \\
& \leqq \nu\left(\left|t^{1}-t^{2}\right|\right)+\sum_{\alpha} \mid \lambda_{\alpha} \sum_{i=1}^{d \alpha} \int_{E_{i}}\left((\beta-1) !\left(t_{\beta}-s_{\beta}\right)\right)^{-1} k_{1_{\alpha}}\left(s_{\beta}\right) d s_{\beta} \\
& \quad+\int_{\sigma_{\beta}}\left\{k_{2_{\alpha}}\left(s_{\beta}\right) w_{1_{\alpha}}\left(\left|t^{1}-t^{2}\right|\right)+w_{2_{\alpha}}\left(\left|x\left(t^{1}, s_{\beta}\right)-x\left(t^{2}, s_{\beta}\right)\right|\right)\right\} d s_{\beta} \mid \\
& \leqq \nu\left(\left|t^{1}-t^{2}\right|\right)+\sum_{\alpha}\left|\lambda_{\alpha}\right|\left[\sum \sigma_{i_{\alpha}}\left(\left|t_{\beta_{i}}^{1}-t_{\beta_{i}}^{2}\right|\right)+k_{2_{\alpha}}\left(w_{1_{\alpha}}\left(\left|t^{1}-t^{2}\right|\right)\right.\right. \\
& \left.\left.\quad+w_{2_{\alpha}} \circ \eta\left(\left|t-t^{2}\right|\right)\right)\right] \leqq \eta\left(\left|t^{1}-t^{2}\right|\right)
\end{aligned}
$$

by $\left(\mathrm{H}_{5}\right)$. (Here, as in $\left(\mathrm{H}_{3}\right), E_{i}$ denotes $\left.\left[t_{\beta_{i}}^{1}, t_{\beta_{i}}^{2}\right] \times D_{\beta_{i}}\right)$. This shows in particular that $\tau x$ is continuous on $G$. Also, for $x \in K$,

$$
\begin{aligned}
|\tau x(t)| \leqq & |f(t)|+\sum_{\alpha}\left|\lambda_{\alpha} T^{\alpha} F_{\alpha}\left(t, s_{\beta}, x\left(t_{\beta}^{\prime}, s_{\beta}\right)\right)\right| \\
\leqq & M_{1}+\sum_{\alpha}\left|\lambda_{\alpha}\right|\left|T_{\beta} H_{\alpha}\left(t, s_{\beta}, x\left(t_{\beta}^{\prime}, s_{\beta}\right)\right)\right| \\
& M_{1}+\sum_{\alpha}\left|\lambda_{\alpha}\right| h_{\beta}^{\beta-1}((\beta-1) !)^{-1} k_{1_{\alpha}} \leqq M_{2} .
\end{aligned}
$$

Thus, $\tau$ maps $K$ into $K$.

Now, let $x_{1}$ and $x_{2}$ be any two elements of $K$. Then, 


$$
\begin{aligned}
\mid \tau x_{1}(t) & -\tau x_{2}(t)\left|\leqq \sum_{\alpha}\right| \lambda_{\alpha}\left[T^{\alpha} F_{\alpha}\left(t, s_{\beta}, x_{1}\right)\right. \\
& \left.-T^{\alpha} F_{\alpha}\left(t, s_{\beta}, x_{2}\right)\right]\left|\leqq \sum_{\alpha}\right| \lambda_{\alpha} \mid k_{2_{\alpha}} w_{2_{\alpha}}\left(\| x_{1}-x_{2}||\right)
\end{aligned}
$$

where

$$
\left\|x_{1}-x_{2}\right\|=\sup \left\{\left|x_{1}(t)-x_{2}(t)\right|: t \in G\right\}
$$

Hence for

$$
x_{1}, x_{2} \in K,\left\|\tau x_{1}-\tau x_{2}\right\| \leqq \sum_{\alpha}\left|\lambda_{\alpha}\right| k_{2_{\alpha}} w_{2_{\alpha}}\left(\| x_{1}-x_{2}||\right)
$$

This shows $\tau$ maps $K$ continuously into it itself.

Now, by Schauder's fixed point theorem there exists at least one $x \in K$ with $\tau x=x$. This concludes the proof of Theorem 1. [Note: Details of above calculations for $n=2$, may be found in [8]].

REMARK. Concerning the hypothesis $\left(\mathrm{H}_{5}\right)$ of above theorem, let us consider the case where $F_{\alpha}$ are Lipschitzian with constants $A_{\alpha}$ in $x$. Then $w_{2_{\alpha}}(\nu)=A_{\alpha} \nu$ (see (4.1)). If

$$
\sum_{\alpha}\left|A_{\alpha} \lambda_{\alpha} h^{\alpha}\right|<1
$$

then

$$
\eta(\theta)=\zeta(\theta)+\sum_{\alpha}\left|\lambda_{\alpha}\right| A_{\alpha} h^{\alpha} \eta(\theta)
$$

yields

$$
\eta(\theta)=\left(1-\sum_{\alpha}\left|A_{\alpha} \lambda_{\alpha} h^{\alpha}\right|\right)^{-1} \zeta(\theta)
$$

and hence by choosing this function as $\eta$ in $\left(\mathrm{H}_{5}\right)$, it follows by Theorem 1 that there exists at least one $x \in K$ satisfying (2.4). Further, in this case, i.e., if $\sum_{\alpha}\left|A_{\alpha} \lambda_{\alpha} h^{\alpha}\right|<1$ then the solution of (2.4) are unique. Indeed, if $x_{1}$ and $x_{2}$ are solutions then $x_{1}=\tau x_{1}$ and $x_{2}=\tau x_{2}$. Now with $w_{2_{\alpha}}(\nu)=A_{\alpha} \nu$, the inequality (4.5) will reduce to

$$
\begin{aligned}
\left\|x_{1}-x_{2}\right\|=\left\|\tau x_{1}-\tau x_{2}\right\| & \leqq \sum_{\alpha}\left|A_{\alpha} \lambda_{\alpha} h^{\alpha}\right|\left\|x_{1}-x_{2}\right\| \\
& <\left\|x_{1}-x_{2}\right\|
\end{aligned}
$$

which is impossible if $x_{1} \neq x_{2}$.

This proves uniqueness.

On the other hand, if $F_{\alpha}$ are known to be Lipschitzian, then by a completely different argument one can prove the existence and uniqueness of continuous solutions of (2.4)-without the further condition $\sum_{\alpha}\left|A_{\alpha} \lambda_{\alpha} h^{\alpha}\right|<1$. Precise formulations follow. We shall omit the proof here, since it is the same as for $L_{p}$-solutions which will be discussed in the next section. 
THeOREM 2. Hypotheses: For each $\alpha, 1 \leqq|\alpha| \leqq N$, let $F_{\alpha}\left(t, s_{\beta}\right.$, $x)=\left(F_{\alpha}^{1}, F_{\alpha}^{2} \cdots F_{\alpha}^{m}\right)$ be defined on $G \times G_{b} \times E^{m}$ where $\beta$ corresponds to $\alpha$. Let $F_{\alpha}$ be continuous in $\left(t_{\beta}, t_{\beta}^{\prime}\right)$ and be measurable in $s_{\beta}$. Let there exist constants $M_{\alpha} \geqq 0$ and functions $A_{\alpha}\left(s_{\beta}\right)$ in $L_{1}\left(G_{\beta}\right)$ such that for all $\left(t, s_{\beta}\right) \in G \times G_{\beta}$ and $x_{1}, x_{2}$ in $E^{m}$, we have

$$
\left|F_{\alpha}\left(t, s_{\beta}, x_{1}\right)-F_{\alpha}\left(t, s_{\beta}, x_{2}\right)\right| \leqq M_{\alpha}\left|x_{1}-x_{2}\right|
$$

and $\left|F_{\alpha}\left(t, s_{\beta}, 0\right)\right| \leqq A_{\alpha}\left(s_{\beta}\right)$. Given a sequence of real numbers $\left\{\lambda_{\alpha}|1 \leqq| \alpha \mid \leqq N\right\}$ and a positive $r$, let $\delta_{r}$ denote $\Sigma \mu_{\alpha} \cdot h^{\alpha}(\alpha !)^{-1}$ where summation extends over $s \leqq|\alpha| \leqq r N$ and $\mu_{\alpha}$ is the coefficient of $\theta^{\alpha}$ in the binomial expansion of $\left(\sum_{1 \leqq|\alpha| \leqq N}\left|\lambda_{\alpha}\right| M_{\alpha} \theta^{\alpha}\right)^{r}$. It is seen that $\delta=$ $\sum_{r=0}^{\infty} \delta_{r}<\infty$. Let $R \geqq 1$ be such that $\delta_{R}<1$. Let $M>0$ be any real number such that

$$
M>\delta\left(1-\delta_{R}\right)^{-1}\left(\|f\|_{c}+\sum_{1 \leqq|\alpha| \leqq N}\left\|\lambda_{\alpha} A_{\alpha}\right\|_{1} h^{\alpha}(\alpha !)^{-1}\right)
$$

where $f$ is a given element of $[C(G)]^{m}$.

Conclusion. Given $f \in[C(G)]^{m}, \lambda_{\alpha}$ real, $1 \leqq|\alpha| \leqq N$, and $M>0$ satisfying (4.6), there exists a unique $x \in[C(G)]^{m}$ with $\|x\| \leqq M$ such that $\tau x=x$ where, as in Theorem 1 ,

$$
\tau x(t)=f(t)+\sum_{1 \leqq|\alpha| \leqq N} \lambda_{\alpha} T^{\alpha} F_{\alpha}\left(t, s_{\beta}, x\left(t_{\beta}^{\prime}, s_{\beta}\right)\right) .
$$

Further, if $f_{1}$ and $f_{2}$ are any two elements of $[C(G)]^{m}$ and if $x_{1}, x_{2}$ are the corresponding solution of $\tau x=x$, then

$$
\left\|x_{1}-x_{2}\right\| \leqq\left(1-\delta_{R}\right)^{-1}\left\|f_{1}-f_{2}\right\| \cdot
$$

Thus, the solutions depend continuously on the "initial" values.

REMARK. The inequality (4.8) is readily obtained by repeated application of the following

$$
\begin{aligned}
\left|x_{1}(t)-x_{2}(t)\right| & =\mid f_{1}(t)-f_{2}(t)+\Sigma \lambda_{\alpha} T^{\alpha}\left[F_{\alpha}\left(t, s_{\beta}, x_{1}\right)\right. \\
-F_{\alpha}\left(t, s_{\beta}, x_{2}\right) \mid & \leqq\left|f_{1}(t)-f_{2}(t)\right|+\sum\left|\lambda_{\alpha}\right| T^{\alpha} M_{\alpha}\left|x_{1}-x_{2}\right| \cdot
\end{aligned}
$$

Thus, for each $r$

$$
\left\|x_{1}-x_{2}\right\| \leqq \delta\left\|f_{1}-f_{2}\right\|+\delta_{r}\left\|x_{1}-x_{2}\right\|
$$

so that

$$
\left\|x_{1}-x_{2}\right\| \leqq \delta\left(1-\delta_{R}\right)^{-1}\left\|f_{1}-\hat{f}_{2}\right\|
$$

where $R$ is such that $\delta_{R}<1$. 
5. $L_{p}$-Solutions $(1 \leqq p \leqq \infty)$. It is of interest to observe that Theorem 2 with slight changes yields unique $L_{p}$-solution for the equation (2.4). The changes needed are made clear by the following.

Theorem 3. Hypotheses: Let $F_{\alpha}$ be as before defined on $G \times G_{\beta} \times$ $E^{m}$; where $\beta$ corresponds to $\alpha$. Let $F_{\alpha}$ be continuous in $t_{\beta}$ and be measurable $\left(t_{\beta}^{\prime}, s_{\beta}\right)$. Let there exist constants $M_{\alpha} \geqq 0$ and functions $A_{\alpha}\left(t_{\beta}^{\prime}, s_{\beta}\right)$ in $\left[L_{p}(G)\right], 1 \leqq p \leqq \infty$, such that for all $\left(t, s_{\beta}\right) \in G \times G_{\beta}$ and $x_{1}, x_{2}$ in $E^{m}$

$$
\left|F_{\alpha}\left(t, s_{\beta}, x_{1}\right)-F_{\alpha}\left(t, s_{\beta}, x_{2}\right)\right| \leqq M_{\alpha}\left|x_{1}-x_{2}\right|
$$

and

$$
\left|F_{\alpha}\left(t, s_{\beta}, 0\right)\right| \leqq A_{\alpha}\left(t_{\beta}^{\prime}, s_{\beta}\right)
$$

Given a sequence of real numbers $\left\{\lambda_{\alpha}|1 \leqq| \alpha \mid \leqq N\right\}$ and a positive integer $r$, let $\delta_{r}$ denote $\sum_{r \leqq|\alpha| \leqq r N} \mu_{\alpha} h^{\alpha}\left(\alpha ! p^{\alpha}\right)^{-1 / p}$ (with $p=1$ in case of $\left.L_{\infty}\right)$ where $\mu_{\alpha}$ is the coefficient of $\theta^{\alpha}$ in the binomial expansion of $\left(\sum_{1 \leqq|\alpha| \leqq N}\left|\lambda_{\alpha}\right| M_{\alpha} \theta^{\alpha}\right)^{r}$. It is seen that $\delta=\sum_{r=1}^{\infty} \delta_{r}<\infty$. Let $R \geqq 1$ be such that $\delta_{R}<1$. Let $M>0$ be any real number such that

$$
M>\delta\left(1-\delta_{R}\right)^{-1}\left(\|f\|_{p}+\sum_{1 \leqq|\alpha| \leqq N}\left\|\lambda_{\alpha} A_{\alpha}\right\|_{p} h^{\alpha}\left(\alpha ! p^{\alpha}\right)^{-1 / p}\right)
$$

where $f$ is a given element of $\left[L_{p}(G)\right]^{m}$. (In the case of $L_{\infty}(G), p$ is taken as 1 in (5.3)).

Conclusion. Given $f$ in $\left[L_{p}(G)\right]^{m}, \lambda_{\alpha}$ real, $1 \leqq|\alpha| \leqq N$ and $M>0$ satisfying (5.3), there exists a unique $x \in\left[L_{p}(G)\right]^{m}$ with $\|x\|_{p} \leqq M$ such that $\tau x=x$, where $\tau$ is defined as in Theorem 2 , by

$$
\tau x(t)=f(t)+\sum_{1 \leqq|\alpha| \leqq N} \lambda_{\alpha} T^{\alpha} F_{\alpha}\left(t, s_{\beta}, x\left(t_{\beta}^{\prime}, s_{\beta}\right)\right) .
$$

Further, if $f_{1}$ and $f_{2}$ are any two elements $\left[L_{p}(G)\right]^{m}$, and $x_{1}, x_{2}$ are the corresponding solutions of $\tau x=x$, then $\left\|x_{1}-x_{2}\right\|_{p} \leqq\left(1-\delta_{R}\right)^{-1} \delta \| f_{1}-$ $f_{2} \|_{p}$.

Proof. Let us observe from (5.1) and (5.2) that

$$
\begin{aligned}
\left|F_{\alpha}\left(t, s_{\beta}, x\right)\right| & \leqq\left|F_{\alpha}\left(t, s_{\beta}, x\right)-F_{\alpha}\left(t, s_{\beta}, 0\right)\right|+\left|F_{\alpha}\left(t, s_{\beta}, 0\right)\right| \\
& \leqq M_{\alpha}|x|+A_{\alpha}\left(t_{\beta}^{\prime}, s_{\beta}\right) .
\end{aligned}
$$

As a consequence of the assumption on $F_{\alpha}$ and the inequalities (5.4), it follows (see $3 . \mathrm{v}$ in $\S 3$ ) that $F_{\alpha}\left(t, s_{\beta}, x\left(t_{\beta}^{\prime}, s_{\beta}\right)\right)$ for fixed $t_{\beta}$ is in $\left[L_{p}(G)\right]^{m}$. Hence $T^{\alpha} F_{\alpha}\left(t, s_{\beta}, x\left(t_{\beta}^{\prime}, s_{\beta}\right)\right)$ is in $\left[L_{p}(G)\right]^{m}$ and consequently $\tau$ maps $\left[L_{p}(G)\right]^{m}$ into itself.

Let us now show that for $x_{1}, x_{2}$ in $\left[L_{p}(G)\right]^{m}$ and any integer $r \geqq 1$, we have 


$$
\left\|\tau^{r} x_{1}-\tau^{r} x_{2}\right\|_{p} \leqq \delta_{r}\left\|x_{1}-x_{2}\right\|_{p}
$$

Indeed,

$$
\begin{aligned}
& \left|\tau x_{1}(t)-\tau x_{2}(t)\right| \\
= & \left|\sum \lambda_{\alpha} T^{\alpha} F_{\alpha}\left(t, s_{\beta}, x_{1}\left(t_{\beta}^{\prime}, s_{\beta}\right)\right)-\sum \lambda_{\alpha} T^{\alpha} F_{\alpha}\left(t, s_{\beta}, x_{2}\left(t_{\beta}^{\prime}, s_{\beta}\right)\right)\right| \\
\leqq & \sum\left|\lambda_{\alpha}\right| T^{\alpha} M_{\alpha}\left|x_{1}-x_{2}\right|\left(t_{\beta}^{\prime}, s_{\beta}\right)
\end{aligned}
$$

and

$$
\left|\tau^{r} x_{1}(t)-\tau^{r} x_{2}(t)\right| \leqq \sum\left|\lambda_{\alpha}\right| T^{\alpha} M_{\alpha}\left|\tau^{r-1} x_{1}-\tau^{r-1} x_{2}\right|\left(t_{\beta}^{\prime}, s_{\beta}\right)
$$

It follows now by induction that

$$
\left|\tau^{r} x_{1}(t)-\tau^{r} x_{2}(t)\right| \leqq\left(\sum\left|\lambda_{\alpha}\right| T^{\alpha} M_{\alpha}\right)^{r}\left|x_{1}-x_{2}\right|\left(t_{\beta}^{\prime}, s_{\beta}\right) .
$$

Now, it follows by using the inequalities (2.1) that

$$
\left\|\tau^{r} x_{1}-\tau^{r} x_{2}\right\|_{p} \leqq \delta_{r}\left\|x_{1}-x_{2}\right\|_{p} \text {. }
$$

The concludes the proof of the inequality (5.5). As a consequence, it is seen that $\tau=\tau^{1}$ is continuous on $\left[L_{p}(G)\right]^{m}$. Further, since $\delta_{r} \rightarrow 0$ as $r \rightarrow \infty$, there is an $R \geqq 1$ such that $\delta_{R}<1$. The corresponding operator $\tau^{R}$ is a contraction on $\left[L_{p}(G)\right]^{m}$.

As a further consequence of (5.5), we have

$$
\left\|\tau^{i+1} x-\tau^{i} x\right\| \leqq \delta_{i}\|\tau x-x\|, x \in\left[L_{p}(G)\right]^{m} i=1,2 \cdots
$$

Hence, for $r \geqq 1$,

$$
\begin{aligned}
\left\|\tau^{r} x\right\| & \leqq\|x\|+\sum_{i=0}^{r-1}\left\|\tau^{i+1} x-\tau^{i} x\right\| \\
& \leqq\|x\|+\|\tau x-x\| \sum_{i=0}^{r-1} \delta_{i} .
\end{aligned}
$$

For $x=0$, this inequality yields

$$
\left\|\tau^{r}(0)\right\| \leqq\left(\sum_{i=0}^{\infty} \delta_{i}\right)\|\tau(0)\|=\delta\|\tau(0)\|
$$

Hence, by (5.5)

$$
\left\|\tau^{r} x\right\| \leqq \delta_{r}\|x\|+\delta\|\tau(0)\|
$$

But, since

$$
|\tau(0)|(t) \leqq|f(t)|+\sum\left|\lambda_{\alpha} T^{\alpha} A_{\alpha}\left(t_{\beta}^{\prime}, s_{\beta}\right)\right|
$$

it follows by the inequality (2.1) that

$$
\|\tau(0)\| \leqq\|f\|+\sum_{1 \leqq|\alpha| \leqq N}\left\|\lambda_{\alpha} A_{\alpha}\right\| h^{\alpha}\left(\alpha ! p^{\alpha}\right)^{-1 / p} .
$$

Thus, by (5.7), 


$$
\left\|\tau^{r} x\right\| \leqq \delta_{r}\|x\|+\delta\left(\|f\|+\sum\left\|\lambda_{\alpha} A_{\alpha}\right\| h^{\alpha}\left(\alpha ! p^{\alpha}\right)^{-1 / p} .\right.
$$

Let us consider the set

$$
X_{M}=\left\{x \in\left[L_{p}(G)\right]^{m} \mid\|x\|_{p} \leqq M\right\} .
$$

This set is mapped into itself by $\tau^{R}$. Indeed it follows from (5.8) that for $x \in X_{M}$

$$
\left\|\tau^{R} x\right\| \leqq M \delta_{R}+M\left(1-\delta_{R}\right)=M .
$$

Now, since $\tau^{R}$ is a contraction on $\left[L_{p}(G)\right]^{m}$, it is so on $X_{M}$. Further, since $X_{M}$ is a closed subspace of the Banach space $\left[L_{p}(G)\right]^{m}$, and thus itself is a Banach space, it follows that there is a unique $x \in X_{M}$ with $\tau^{r} x=x$. But since $\tau$ is a continuous operator on $\left[L_{p}(G)\right]^{m}$ it follows (see 3. ii in $\S 3$ ) that $\tau x=x$. This concludes the proof of existence and uniqueness.

Let $f_{1}$ and $f_{2}$ be any two elements of $\left[L_{p}(G)\right]^{m}$ and let $x_{1}$ and $x_{2}$ be the corresponding solutions of (2.4). Let $f=\left|f_{1}-f_{2}\right|$ and $x=$ $\left|x_{1}-x_{2}\right|$. It is seen that

$$
x(t) \leqq f(t)+\left(\sum\left|\lambda_{\alpha}\right| T^{\alpha} M_{\alpha}\right) x(t) .
$$

Applying the inequality again, we get

$$
\begin{aligned}
x(t) & \leqq f(t)+\sum\left|\lambda_{\alpha}\right| T^{\alpha} M_{\alpha}\left(f(t)+\left(\sum\left|\lambda_{\alpha}\right| T^{\alpha} M_{\alpha}\right) x(t)\right) \\
& =\left(1+\sum\left|\lambda_{\alpha}\right| T^{\alpha} M_{\alpha}\right) f(t)+\left(\sum\left|\lambda_{\alpha}\right| T^{\alpha} M_{\alpha}\right)^{2} x(t) .
\end{aligned}
$$

In general for $r \geqq 1$,

$$
\begin{aligned}
x(t) \leqq[1 & \left.+\left(\sum\left|\lambda_{\alpha}\right| T^{\alpha} M_{\alpha}\right)+\cdots+\left(\sum\left|\lambda_{\alpha}\right| T^{\alpha} M_{\alpha}\right)^{r-1}\right] f(t) \\
& +\left(\sum\left|\lambda_{\alpha}\right| T^{\alpha} M_{\alpha}\right)^{r} x(t) .
\end{aligned}
$$

But then

$$
\|x\|_{p} \leqq\|f\|_{p}\left(1+\delta_{1}+\delta_{2}+\cdots+\delta_{r-1}\right)+\delta_{r}\|x\|_{p} .
$$

If $R$ is such that $\delta_{R}<1$, then

$$
\|x\|_{p}\left(1-\delta_{R}\right) \leqq\|f\|_{p}\left(1+\delta_{1}+\cdots+\delta_{r-1}\right) \leqq \delta\|f\|_{p}
$$

thus,

$$
\|x\|_{p} \leqq \delta\left(1-\delta_{R}\right)^{-1}\|f\|_{p}
$$

i.e.,

$$
\left\|x_{1}-x_{2}\right\|_{p} \leqq \delta\left(1-\delta_{R}\right)^{-1}\left\|f_{1}-f_{2}\right\|_{p} .
$$

This concludes the proof of the theorem. 
6. General Remarks. A. The arguments of the previous sections, when applied to a space of analytic functions yield a unique analytic solution of (2.4) provided the function $F_{\alpha}$ are assumed linear in $x$ with analytic coefficients. Precise formulations follow:

THEorem 4. Let $G=\left\{t \in E^{n}|| t_{i} \mid \leqq h_{i}, i=1,2 \cdots n\right\}$ and let $f(t)$, $A_{\alpha}(t), 1 \leqq|\alpha| \leqq N$ be functions analytic on an open rectangle $R_{1}=$ $\left\{t \in E^{n}|| t_{i} \mid<H_{i}^{\prime}, i=1,2 \cdots n\right\}$ containing $G$. Then there exists a unique function $x(t)$ analytic on $G$ and satisfying

$$
x(t)=f(t)+\sum_{1 \leqq \alpha_{i} \leqq N} \lambda_{\alpha} T^{\alpha}\left(A_{\alpha} x\right)\left(t_{\beta}^{\prime}, s_{\beta}\right) .
$$

Proof. Let $R=\left\{t \in E^{n}|| t_{i} \mid \leqq H_{i}, i=1,2 \cdots n\right\}$ be such that $G \subset$ $R \subset R_{1}$. Let $D=\left\{\zeta \in C^{n}|| \zeta_{i} \mid \leqq H_{i}, i=1,2 \cdots n\right\} \subset C^{n}$, where $C$ denotes as usual, the set of complex numbers. Let $O(D)$ denote the set of all functions holomorphic in $D$. Then $O(D)$ is a Banach space with the norm given by

$$
\|x\|=\sum_{|\alpha|=0}^{\infty}\left|a_{\alpha}\right| H^{\alpha} \text { for } x=\sum_{|\alpha|=0}^{\infty} a_{\alpha} \zeta^{\alpha}
$$

Let $\widetilde{f}(\zeta)$ and $\widetilde{A}_{\alpha}(\zeta)$ be natural holomorphic extensions in $D$, of $f(t)$ and $A_{\alpha}(t)$ respectively. Let $\tau$ be operator defined on $O(D)$ by

$$
\tau x(\zeta)=\widetilde{f}(\zeta)+\sum_{1 \leqq \alpha \leqq N} \lambda_{\alpha} \widetilde{T}_{\alpha}\left(\widetilde{A}_{\alpha} x\right)\left(\zeta_{\beta}^{\prime}, \xi_{\beta}\right)
$$

where $\widetilde{T}_{\alpha}=\widetilde{T}_{1}^{\alpha_{1}} \cdots \widetilde{T}_{n}^{\alpha_{n}}$ is analogous to $T_{\alpha}$; for example,

$$
\widetilde{T}_{i} x(\zeta)=\int_{-H_{i}}^{\zeta_{i}} x\left(\zeta_{i}^{\prime}, \xi_{i}\right) d \xi_{i}, \quad i=1,2 \cdots n .
$$

It is to be noted that for $x \in O(D)$, the integral defining $\widetilde{T}_{i}$, does not depend on the path.

It is clear that $\tau$ maps $O(D)$ into itself. Further, for any positive integer $r$ and any $x_{1}, x_{2} \in O(D)$, we have

$$
\left\|\tau^{r} x_{1}-\tau^{r} x_{2}\right\| \leqq \sum_{r \leqq}^{\infty} \sum_{\alpha \mid \leqq r .} \mu_{\alpha} H^{\alpha}(\alpha !)^{-1}\left\|x_{1}-x_{2}\right\|
$$

where $\mu_{\alpha}$ is the coefficient of $\theta^{\alpha}$ in the binomial expansion of $\left(\sum_{1 \leqq|\alpha| \leqq N}\left|\lambda_{\alpha}\right| A_{\alpha} \theta^{\alpha}\right)^{r}$-here, $A_{\alpha}=\operatorname{Sup}\left\{\left|A_{\alpha}(\zeta)\right|: \zeta \in D\right\}$. [To obtain the above inequality, we observe that if

$$
x_{1}-x_{2}=\sum_{|\nu|=0} a_{\nu} \zeta^{\nu}
$$

then 


$$
\begin{aligned}
\left|\widetilde{T}_{\alpha}\left(x_{1}-x_{2}\right)\right| & \leqq \mid \sum_{\nu} a_{\nu} \zeta^{\alpha+\nu} \nu !((\alpha+\nu) !)^{-1} \\
& \leqq \sum_{\nu}\left|a_{\nu}\right| H^{\alpha+\nu} \nu !((\alpha+\nu) !)^{-1} \\
& \left.\leqq \sum_{\nu}\left|a_{\nu}\right| H^{\nu} H^{\alpha}(\alpha !)^{-1}\right] .
\end{aligned}
$$

It follows that $\left\|\tau^{r} x_{1}-\tau^{r} x_{2} \mid \leqq \delta_{r}\right\| x_{1}-x_{2} \|$ where $\delta_{r}=\sum_{r \leqq|\alpha| \leqq r N} \mu_{\alpha} H^{\alpha}(\alpha !)^{-1}$. Since this is true for any $x_{1}, x_{2} \in O(D)$ and $\sum_{r=1}^{\infty} \delta_{r}<\infty$-(it is majorised by an exponential function)-and since $O(D)$ is a Banach space, it follows by statement (3. i) that $\tau$ has a unique fixed point in $O(D)$. If $\widetilde{x}(\zeta)$ denotes this fixed point, and if $x(t)$ denotes the restriction of $\widetilde{x}(\zeta)$ for $\zeta$ real, it is clear that $x(t)$ is the unique analytic solution of (6.1).

B. The canonical form suggested in this paper is very similar to the form studied by Kasatkina [5]. It is to be noted, however, that the notation proposed here simplifies the exposition. Further, it takes care of repeated itegrals also, in a natural way. Of course, a repeated integral can be transformed into a single integral and the author found that it made no difference in the estimates obtained here. The arguments remain the same too.

C. A function $v \in L_{p}(G)$ will be said to be the generalized partial derivatives of order $\alpha=\left(\alpha_{1} \cdots \alpha_{n}\right)$ of a function $u \in L_{p}(G)$, or $v=D^{\alpha} u$, in the usual sense (C. B. Morrey [7], S. L. Sobolev [9]). We mention here that generalized partial derivatives of order one, have a simple characterization. A function $x_{t_{i}} \in L_{p}(G)$ is the generalized partial derivative of $x \in L_{p}(G)$ with respect to $t_{i}$ if and only if for almost all closed rectangles $R \subset G, R=\left\{t \mid c_{i} \leqq t_{i} \leqq d_{i}, i=1,2 \cdots n\right\}$, we have

$$
\int_{R} x_{t_{i}} d t=\int_{c_{i}^{\prime}}^{d_{i}^{\prime}}\left[x\left(d_{i}, s\right)-x\left(c_{i}, s\right)\right] d s
$$

where $c_{i}^{\prime}$ and $d_{i}^{\prime}$ are defined as usual, by $c=\left(c_{i}, c_{i}^{\prime}\right)$ and $d=\left(d_{i}, d_{i}^{\prime}\right)$. Here the expression "for almost all rectangles $R=[c, d]$ " means that the set of all $(c, d)$ has the same measure as $G \times G$.

It is not difficult to verify that if $x \in L_{p}(G)$ then $T_{i} x$ possesses generalized partial derivative with respect to $t_{i}, i=1,2 \cdots n$. Consequently, if $x$ is an $L_{p}$-solution of an equation of the form

$$
x(t)=f(t)+T_{i} \Sigma \lambda_{\alpha} T^{\alpha} F_{\alpha}(t, s, x(t, s))
$$

for a given $i, i=1,2 \cdots n$, and if $f$ possesses generalized partial derivative with respect to $t_{i}$, then $x$ also possesses generalized partial derivative with respect to $t_{i}$. An example of such a situation is the equivalent of Darboux Problem, 


$$
z(x, y)=\int_{0}^{x} \int_{0}^{y} F(\alpha, \beta, z(\alpha, \beta)) d \alpha d \beta .
$$

Any $L_{p}$-solution of this equation possesses generalized partials with respect to both $x$ and $y$.

Appendix. We shall discuss now the application of our existence theorems to the special case of the classical Darboux problem in a rectangle $G=[a, a+h] \times[b, b+k] \subset E^{2}$ :

$$
z_{x y}^{i}=F_{i}\left(x, y, z, z_{x}, z_{y}\right),(x, y) \in G,
$$

$$
\begin{aligned}
z^{i}(x, b) & =\varphi^{i}(x) ; z^{i}(a, y)=\psi^{i}(y) ; \varphi^{i}(a)=\psi^{i}(b), \\
z & =\left(z^{1}, z^{2}, \cdots z^{n}\right) ; i=1,2 \cdots n
\end{aligned}
$$

The precise results which will be stated below as corollaries of our Theorem 3 of $\S 5$ will be applied in the optimal control problem mentioned in the introduction. We shall need the following hypothesis on (A. 1) to be able to apply Theorem $3, \S 5$ and obtain solutions of (A. 1) belonging to a Sobolev class (see [2]).

$\left(\mathrm{H}_{1}\right)$ : The functions $\varphi(x)=\left(\varphi^{1}, \varphi^{2}, \cdots \varphi^{n}\right)$, and $\psi(y)=\left(\psi^{1}, \psi^{2}, \cdots\right.$ $\left.\psi^{n}\right)$ are defined and absolutely continuous on $[a, a+h]$ and $[b, b+k]$ respectively. The derivatives $\varphi_{x}$ and $\psi_{y}$ which exist almost everywhere, belong to $L_{p}([a, a+h])$ and $L_{p}([b, b+k])$ respectively; here $1 \leqq p \leqq \infty$. Further $\varphi(a)=\psi(b)$.

$\left(\mathrm{H}_{2}\right): \quad F=F(x, y, z, r, t)=\left(F_{1}, F_{2}, \cdots, F_{n}\right)$ is defined for all $(x$, $y) \in G$ and $(z, r, t) \in E^{3 n}$. For each $i, F_{i}$ is measurable in $(x, y)$ for fixed $(z, r, t) \in E^{3^{n}}$.

$\left(\mathrm{H}_{3}\right)$ : There exists a constant $K>0$ such that for $(x, y) \in G$ and $\left(z_{1}, r_{1}, t_{1}\right),\left(z_{2}, r_{2}, t_{2}\right) \in E^{3 n}$, we have

$$
\left|F\left(x, y, z_{1}, r_{1}, t_{1}\right)-F\left(x, y, z_{2}, r_{2}, t_{2}\right)\right| \leqq K\left(\left|z_{1}-z_{2}\right|+\left|r_{1}-r_{2}\right|+\left|t_{1}-t_{2}\right|\right) \text {. }
$$

$\left(\mathrm{H}_{4}\right):$ Let $F(x, y, 0,0,0) \in\left[L_{p}(G)\right]^{n}$.

REMARK. One may assume, instead of $\left(\mathrm{H}_{3}\right)$ that, there exist constants $K_{1 j}, K_{2 j}, K_{3 j}>0$ with $j=1,2, \cdots, n$, such that,

$$
\begin{aligned}
& \left|F_{i}\left(x, y, z_{1}, r_{1}, t_{1}\right)-F_{i}\left(x, y, z_{2}, r_{2}, t_{2}\right)\right| \\
\leqq & \sum_{j=1}^{n}\left[K_{1 j}\left|z_{1}^{j}-z_{2}^{j}\right|+K_{2 j}\left|r_{1}^{j}-r_{2}^{j}\right|+K_{3 j}\left|t_{1}^{j}-t_{2}^{j}\right|\right] .
\end{aligned}
$$

But with no loss of generality we may set $K_{1 j}=K_{2 j}=K_{3 j}=K^{1}>0$ and $K=n K^{1}$ so that the above inequality reduces to $\left(\mathrm{H}_{3}\right)$. 
Let $W_{p}^{1}(G)$ denote the Sobolev space of all $z \in L_{p}(G)$ with first order generalized partial derivatives (see $\S 6$ ) $z_{x}, z_{y}$ belonging to $L_{p}(G)$. Let $\|z\|=\|z\|_{p}+\left\|z_{x}\right\|_{p}+\left\|z_{y}\right\|_{p}$ denote the norm in $\left[W_{p}^{1}(G)\right]^{n}$.

THeOREM 5. Let the hypotheses $H_{1}-H_{4}$ hold. Then, there exists a unique $z \in\left[W_{p}^{1}(G)\right]^{n}, 1 \leqq p \leqq \infty$ (same as in $\left.\left(\mathrm{H}_{1}\right)\right)$, such that (i) the generalized partial derivative $z_{x y}^{i}(x, y)$ exists and equals $F_{i}\left(x, y, z, z_{x}, z_{y}\right)$ a.e. in $G$ and (ii) $z(x, b)=\varphi(x) ; z(a, y)=\psi(y)$.

Further,

$$
\begin{aligned}
\|z\| \leqq & \left(1-\delta_{r}\right)^{-1} \delta\left[k^{1 / p}\left(\left\|\varphi_{x}\right\|_{p}+2^{-1}\|\varphi\|_{p}\right)\right. \\
& \left.+h^{1 / p}\left(\left\|\psi_{y}\right\|_{p}+2^{-1}\|\psi\|_{p}\right)+(h+k)\|s(x, y)\|_{p}\right]
\end{aligned}
$$

where $s(x, y)=F(x, y, 0,0,0) ; \delta=\sum_{n=1}^{\infty} \delta_{n} ; \delta_{n}=[n / 2]^{-1} \rho^{n}$ with $\rho=(2 K+$ 1) $\times\left(p^{-1 / p}\right)\left(h^{p}+k^{p}\right)^{1 / p}$ if $1<p<\infty$ and $\rho=\left(k+2^{-1}\right)(h+k)$ if $p=1$ or $p=\infty$. The number $k$ here is same as in $\left(\mathrm{H}_{3}\right)$ and the number $R$ in (A.2) is that positive integer for which $\delta_{R}<1$.

If $\left(\varphi_{1}, \psi_{1}\right)$ and $\left(\varphi_{2}, \psi_{2}\right)$ are any two pairs of functions satisfying $\left(\mathrm{H}_{1}\right)$ and if $z_{1}, z_{2}$ are the corresponding solutions of (A.1) then

$$
\|z\| \leqq\left(1-\delta_{R}\right)^{-1} \delta\left[k^{1 / p}\left(\left\|\varphi_{x}\right\|_{p}+2^{-1}\|\varphi\|_{p}\right)+h^{1 / p}\left(\left\|\psi_{y}\right\|_{p}+2^{-1}\|\psi\|_{p}\right)\right]
$$

where

$$
z=z_{1}-z_{2} ; \varphi=\varphi_{1}-\varphi_{2} ; \psi=\psi_{1}-\psi_{2} ;
$$

$\delta^{\prime}$ s are as above.

Proof. Let us consider the integral equation

$$
\begin{aligned}
z(x, y)= & \varphi(x)+\psi(y)-\varphi(\alpha) \\
& +\int_{a}^{x} \int_{b}^{y} F\left(\alpha, \beta, z(\alpha, \beta), z_{x}(\alpha, \beta), z_{y}(\alpha, \beta)\right) d \alpha d \beta
\end{aligned}
$$

where $z_{x}$ and $z_{y}$ are understood as generalized partials of $z$. Clearly, any solution of (A.4) (which is necessarily continuous on $G$ and hence in $\left.\left[L_{p}(G)\right]^{n}\right)$ has, indeed, generalized partials $z_{x}, z_{y}$ which satisfy the following

$$
w_{1}(x, y)=2^{-1}(\varphi(x)+\psi(y))+2^{-1} \int_{a}^{x} w_{2}(\alpha, y) d \alpha+2^{-1} \int_{b}^{y} w_{3}(x, \beta) d \beta
$$

$$
\begin{aligned}
& w_{2}(x, y)=\varphi_{x}(x)+\int_{a}^{x} 0 . d \alpha+\int_{b}^{y} F(x, \beta, w(x, \beta)) d \beta \\
& w_{3}(x, y)=\psi_{y}(y)+\int_{a}^{x} F(\alpha, y, w(\alpha, y)) d \alpha+\int_{b}^{y} 0 . d \beta .
\end{aligned}
$$

Where

$$
w_{1}=z ; w_{2}=z_{x} ; w_{3}=z_{y} ; w=\left(w_{1}, w_{2}, w_{3}\right) \text {. }
$$


Further, $z_{x y}$ exists and equals $F\left(x, y, z, z_{x}, z_{y}\right)$ a.e. in $G$. Thus, every $\left[W_{p}^{1}(G)\right]^{n}$ solution of (A.4) (and hence of (A. 1)) corresponds in a unique manner (as in (A. 6)) to a $\left[L_{p}(G)\right]^{3 n}$ solution $w=\left(w_{1}, w_{2}, w_{3}\right)$ of (A. 5). Now, the system of equations (A. 5) is exactly in the canonical form (2.4). Since the hypotheses $H_{1}-H_{4}$ guarantee the assumptions in Theorem 3, $\S 5$, existence of a unique solution $w \in\left[L_{p}(G)\right]^{3 n}$ and hence of the corresponding $z \in\left[W_{p}^{1}(G)\right]^{n}$ is concluded.

The norm bound (A. 2) for the solution $z$ follows from the inequality (5.3) with the observation that in the present case, $\|w\|_{p}=\|z\|$; $N=1 ; A_{\alpha}(x, y)=F(x, y, 0,0,0) ; \lambda_{\alpha}=1 ; f=\left(2^{-1}(\varphi+\psi), \varphi_{x}, \psi_{y}\right) ; \alpha=$ $(1,0)$ or $(0,1)$. It is to be noted that $\|\cdot\|$ in $(5.3)$ denotes the norm in $L_{p}(G)$ while $\|\varphi\|$ in (A.2) denotes the norm of $\varphi(x)$ in $L_{p}([a, a+h])$, and so on.

The same observation leads us from the conclusion of Theorem 3, $\S 5$ to the inequality (A. 3). This concludes the proof of Theorem 5 .

Special cases: (i) If $F$ of $\left(\mathrm{H}_{2}\right)$ does not depend on $r$ and $t$, then (A. 4) is itself in the canonical form (2.4). In this case, the norm bound for the solution $z$ is given by

$$
\begin{gathered}
\|z\| \leqq \delta\left(1-\delta_{R}\right)^{-1}\left[2^{-1}\left(k^{1 / p}\|\varphi\|+h^{1 / p}\|\psi\|\right)+p^{-1 / p}\left(h k\|s\|_{p}\right.\right. \\
\left.\left.+\left\|\varphi_{x}\right\| h k^{1 / p}+\left\|\psi_{y}\right\| k h^{1 / p}\right) / 2\right],
\end{gathered}
$$

where

$$
\begin{aligned}
\delta_{r} & =(r !)^{-2}(K h k)^{r} \text { if } p=1 \text { or } p=\infty \text { and } \\
\delta_{r} & =\left(r ! p^{r}\right)^{-2 / p}(k h k)^{r} \text { if } 1<p<\infty \text { and } \\
\delta & =\sum_{n=1}^{\infty} \delta_{n}, \text { as before. }
\end{aligned}
$$

(ii) Let $U \subset E^{m}$ and let $\Gamma$ be any set of measurable functions $v: G \rightarrow U$. Let $f=f(x, y, z, r, t, u)$ be defined on $G \times E^{3 n} \times U$ and let $f$ be measurable in $(x, y)$, continuous in $u$, and Lipschitzian (as in $\left(\mathrm{H}_{3}\right)$ ) in $(z, r, t)$. Let for each $v \in \Gamma$, the function $f(x, y, 0,0,0, v(x, y))$ belong to $\left[L_{p}(G)\right]^{n}$. For a given $v \in \Gamma$, define

$$
F(x, y, z, r, t)=f(x, y, z, r, t, v(x, y)) \text {. }
$$

Then $F$ satisfies $H_{2}, H_{3}, H_{4}$. By applying Theorem 5, to this $F$ we obtain a unique solution $z$ of (A.1) corresponding to the data $\varphi$, $\psi$ and $v$ (which defines $F$ ). The inequality (A.2) gives the norm-bound on $z$, as before. If $v_{1}$ and $v_{2}$ are any two elements of $\Gamma,\left(\varphi_{1}, \psi_{1}\right)$ and $\left(\varphi_{2}, \psi_{2}\right)$ satisfy $\left(\mathrm{H}_{1}\right)$ and if $z_{i}$ is the solution of (A. 1) corresponding to the data $\left(\Phi_{i}, \psi_{i}, v_{i}\right), i=1,2$ then $z=z_{1}-z_{2}$ satisfies the inequality (A. 2) with $\varphi=\varphi_{1}-\varphi_{2} ; \psi=\psi_{1}-\psi_{2}$ and 


$$
s(x, y)=\left|f\left(x, y, z_{1}, z_{1 x}, z_{1 y}, v_{1}\right)-f\left(x, y, z_{1}, z_{1 x}, z_{1 y}, v_{2}\right)\right|
$$

Pointwise estimates: Since any solution $z$ of (A.1) satisfies the integral equation (A.4), it is absolutely continuous in the sense of Tonelli. Hence, there is a set $E \subset G$, with meas $E=0$ such that for $\left(x_{0}, y_{0}\right) \in G-E$, we have in view of $\left(\mathrm{H}_{3}\right)$,

$$
\begin{aligned}
\left|z_{x}\left(x_{0}, y_{0}\right)\right| \leqq \mid \varphi_{x}\left(x_{0}\right) & +\int_{b}^{y_{0}}[s+k(|z| \\
& \left.\left.+\left|z_{x}\right|+\left|z_{y}\right|\right)\right]\left(x_{0}, \beta\right) d \beta
\end{aligned}
$$

where $s(x, y)$ denotes $|F(x, y, 0,0,0)|$. Similar inequality holds for $z_{y}\left(x_{0}\right.$, $\left.y_{0}\right)$. Further $z(x, y)=\psi(y)+\int_{a}^{x} z_{x}(\alpha, y) d \alpha=\varphi(x)+\int_{b}^{y} z_{y}(x, \beta) d \beta$. Using these facts along with the repeated application of Gronwall's lemma one finds that

$$
|z(x, y)| \leqq 2^{-1}\left[\|\varphi\|_{c}+\|\psi\|_{c}+e^{K(h+k)} \iint_{G} s(\alpha, \beta) d \alpha d \beta\right.
$$

$$
\begin{aligned}
& \left.+A_{5}\left(A h+A k+e^{K(h+k)}\right)\right] \\
& \quad\left|z_{x}(x, y)\right| \leqq \theta_{1}(x)+A A_{5} \text { and }\left|z_{y}(x, y)\right| \leqq \theta_{2}(y)+A A_{5}
\end{aligned}
$$

where

$$
\begin{aligned}
\theta_{1}(x) & =e^{K k}\left[\left|\varphi_{x}(x)\right|+K k|\varphi(x)|+\int_{b}^{b+k} s(x, \beta) d \beta\right] \\
\theta_{2}(y) & =e^{K h}\left[\left|\psi_{y}(y)\right|+K k|\psi(y)|+\int_{a}^{a+h} s(\alpha, y) d \alpha\right] \\
A_{5} & =\left\|\varphi_{x}\right\|_{p} h^{1 / q}+\left\|\psi_{y}\right\| k^{1 / q}+\left(\|\varphi\|_{c}+\|\|_{c}\right) K h k+\iint_{G} s(\alpha, \beta) d \alpha d \beta
\end{aligned}
$$

and $A$ is a constant depending only on $K, h$ and $k$. In the above $\|\cdot\|_{0}$ denotes the supremum norm.

Dependence on data: Let $z_{i}$ denote, as before, the solution of (A. 1), corresponding to the data $\left(\varphi_{i}, \psi_{i}, v_{i}\right), i=1,2$. ( $F$ being given by (A. 7).) It is seen then that $z_{x}=z_{1 x}-z_{2 x}$ and $z_{y}=z_{1 y}-z_{2 y}$ satisfy the inequalities (A.9) and hence pointwise estimates for $z=z_{1}-z_{2}$ and its derivatives are also given by (A.10) where $z, \varphi, \psi$ and $s$ are understood as follows:

$$
\begin{aligned}
z & =z_{1}-z_{2} ; \varphi=\varphi_{1}-\varphi_{2} ; \dot{\psi}=\psi_{1}-\psi_{2} ; \\
s(x, y) & =\left|f\left(x, y, z_{1 x}, z_{1 y}, v_{1}\right)-f\left(x, y, z_{1}, z_{1 x}, z_{1 x}, v_{2}\right)\right| .
\end{aligned}
$$

\section{REFERENCES}

1. F. F. Bonsall, Lectures on some fixed point theorems of functional analysis, notes by K. B. Vedak, Tata Institute of Fundamental Research, Bombay, India 1962. 
2. L. Cesari, Sobolev spaces and multidimensional Lagrange problems of optimization, Annali Scoula Normale Sup Pisa, 22 (1968), 193-227.

3. T. H. Gronwall, An integral equation of the Volterra type, Annals of Math. ser. 2, 16 No. 3 (1915), 119-122.

4. R. C. Gunning and H. Rossi, Analytic Functions of Several Complex Variables, Prentice Hall Inc., New Jersey, 1965.

5. N. V. Kasatkina, Uniqueness theorems for a system of multidimensional Volterra integral equations, Differentialnye Uravneniya, 3, No. 2 (1967), 273-277.

6., M. A. Krasnoselskii, Topological Methods in the Theory of Nonlinear Integral Equations, Engl. tr. ed. by J. Burlak, Pergammon Press, New York 1964.

7. C. B. Morrey, Jr., Multiple Integrals in the Calculus of Variations, Springer Verlag, New York, 1966.

8. M. B. Suryanarayana, Optimization problems with hyperbolic partial differential equations, Ph. D. thesis, University of Michigan, Ann Arbor, 1969.

9. S. L. Sobolev, Applications of functional analysis in mathematical physics, Izd 1950, Amer. Math. Soc. Transl., Vol. 7, Providence, R. I. 1963.

10. W. Walter, Differential-und Integral-Ungleichungen und ihre anwendung bei Abschätzungs-und Eindeutigkeitsproblemen, Berlin, Springer 1964.

11. Arthur Wouk, Direct iteration, existence and uniqueness. Nonlinear integral equations, (Proc. Advanced Seminar conducted by Math. Research Center, U. S. Army, University of Wisconsin, Wisconsin 1963), 3-33, University of Wisconsin Press, Madison, Wisconsin 1964.

12. R. H. J. Germany, Sur les equations integrales, Memoires Soc. Roy. So. Liege, Ser. 3, 13, fase 4, (1926), 1-26; Sur les functions de Riemann associaees aux systemes d'equations aux derivees partielles et d'equations integro differentielles dir second ordre a' deux variables independantes.

Received January 7, 1971. This research was partially supported by research project U. S. AFOSR-69-1662 at the University of Michigan. The author is greatly indebted to Professor Cesari for his valuable guidance and constant encouragement during the writing of this paper.

EASTERN Michigan UNIVERSITY 


\title{
PACIFIC JOURNAL OF MATHEMATICS
}

\author{
EDITORS
}

H. SAMELSON

Stanford University

Stanford, California 94305

C. R. HOBBY

University of Washington

Seattle, Washington 98105

\section{J. DugundJI}

Department of Mathematics

University of Southern California

Los Angeles, California 90007

RICHARD ARENS

University of California

Los Angeles, California 90024

\section{ASSOCIATE EDITORS}
E. F. BeCKeNBACH
B. H. NeUmanN
F. WoLF
K. YoSHIDA

\section{SUPPORTING INSTITUTIONS}

\author{
UNIVERSITY OF BRITISH COLUMBIA \\ CALIFORNIA INSTITUTE OF TECHNOLOGY \\ UNIVERSITY OF CALIFORNIA \\ MONTANA STATE UNIVERSITY \\ UNIVERSITY OF NEVADA \\ NEW MEXICO STATE UNIVERSITY \\ OREGON STATE UNIVERSITY \\ UNIVERSITY OF OREGON \\ OSAKA UNIVERSITY
}

\author{
UNIVERSITY OF SOUTHERN CALIFORNIA \\ STANFORD UNIVERSITY \\ UNIVERSITY OF TOKYO \\ UNIVERSITY OF UTAH \\ WASHINGTON STATE UNIVERSITY \\ UNIVERSITY OF WASHINGTON

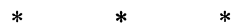 \\ AMERICAN MATHEMATICAL SOCIETY \\ NAVAL WEAPONS CENTER
}

The Supporting Institutions listed above contribute to the cost of publication of this Journal, but they are not owners or publishers and have no responsibility for its content or policies.

Mathematical papers intended for publication in the Pacific Journal of Mathematics should be in typed form or offset-reproduced, (not dittoed), double spaced with large margins. Underline Greek letters in red, German in green, and script in blue. The first paragraph or two must be capable of being used separately as a synopsis of the entire paper. The editorial "we" must not be used in the synopsis, and items of the bibliography should not be cited there unless absolutely necessary, in which case they must be identified by author and Journal, rather than by item number. Manuscripts, in duplicate if possible, may be sent to any one of the four editors. Please classify according to the scheme of Math. Rev. Index to Vol. 39. All other communications to the editors should be addressed to the managing editor, Richard Arens, University of California, Los Angeles, California, 90024.

50 reprints are provided free for each article; additional copies may be obtained at cost in multiples of 50 .

The Pacific Journal of Mathematics is published monthly. Effective with Volume 16 the price per volume (3 numbers) is $\$ 8.00$; single issues, $\$ 3.00$. Special price for current issues to individual faculty members of supporting institutions and to individual members of the American Mathematical Society: $\$ 4.00$ per volume; single issues $\$ 1.50$. Back numbers are available.

Subscriptions, orders for back numbers, and changes of address should be sent to Pacific Journal of Mathematics, 103 Highland Boulevard, Berkeley, California, 94708.

PUBLISHED BY PACIFIC JOURNAL OF MATHEMATICS, A NON-PROFIT CORPORATION

Printed at Kokusai Bunken Insatsusha (International Academic Printing Co., Ltd.), 270, 3-chome Totsuka-cho, Shinjuku-ku, Tokyo 160, Japan. 


\section{Pacific Journal of Mathematics}

\section{Vol. 41, No. $3 \quad$ BadMonth, 1972}

George E. Andrews, Two theorems of Gauss and allied identities proved arithmetically.................................. 563

Stefan Bergman, On pseudo-conformal mappings of circular domains . . . . 579

Beverly L. Brechner, On the non-monotony of dimension ............ 587

Richard Anthony Brualdi and John H. Mason, Transversal matroids and Hall's theorem .................................... 601

Philip Throop Church and James Timourian, Differentiable maps with

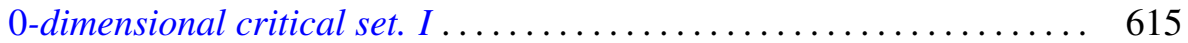

John H. E. Cohn, Squares in some recurrent sequences ............. 631

Robert S. Cunningham, Edgar Andrews Rutter and Darrell R. Turnidge, Rings of quotients of endomorphism rings of projective modules ......

Eldon Dyer and S. Eilenberg, An adjunction theorem for locally equiconnected spaces................................... 669

Michael W. Evans, On commutative P. P. rings................. 687

Ronald Lewis Graham, Hans Sylvain Witsenhausen and Hans Zassenhaus, On tightest packings in the Minkowski plane ..................

Stanley P. Gudder, Partial algebraic structures associated with

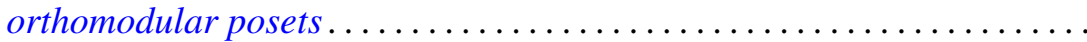

Karl Edwin Gustafson and Gunter Lumer, Multiplicative perturbation of

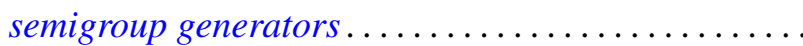

Kurt Kreith and Curtis Clyde Travis, Jr., Oscillation criteria for selfadjoint elliptic equations...

Lawrence Louis Larmore, Twisted cohomology theories and the single obstruction to lifting...........................

Jorge Martinez, Tensor products of partially ordered groups . . .

Robert Alan Morris, The inflation-restriction theorem for Amitsur cohomology ...

Leo Sario and Cecilia Wang, The class of $(p, q)$-biharmonic functions ...

Manda Butchi Suryanarayana, On multidimensional integral equations of

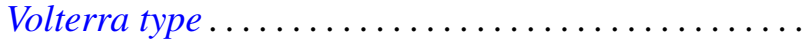

